\title{
Implementation of Investigation Teaching and Cultivation
}

\author{
Size Li \\ School of Mechanical Engineering College, Tianjin University of Commerce, Tianjin, 300134, China
}

Zeqin Liu*

Key Laboratory of Tianjin Refrigeration Technology, Tianjin, 300134, China

\begin{abstract}
The competition in overall national strength focused on implementing research teaching and cultivating innovative talents of soft power is becoming increasingly fierce. To cope with the rapid economic development, cultivation of innovative talents has become an integral element of modern teaching philosophy and become more mainstream direction of educational reform in Chinese universities. The paper based on students of science and engineering in commercial colleges explored the significance of research teaching, limiting factors and development direction to provide the reference and opinions for educational reform of research teaching.
\end{abstract}

KEYWORDS: research teaching; innovative talents; educational reform

\section{INTRODUCTION}

Based on the economy, science and technology as the guide, the strategy of making China stronger by producing more outstanding personnel has become a serious problem in Chinese colleges and universities. As the Harvard University President Rudenstine (2009) said:" the best education should not only help us to be more creative in the professional field, it also should make us better at thought, pursuit ideals and have insight, at last become better and more successful people."[2] In view of this, our universities should promote research teaching as an opportunity to give full play to the innovation, autonomy, efficiency in the process of study and vigorously develop innovative talents to adapt to the application of social development.

\section{BASIC CONCEPTS}

Research-oriented teaching is a teaching method, which refers to attracting students to actively explore, think and practice through the creation of a similar scenario and ways in the teaching activity of scientific research, so as to the abilities of learning, practice and innovation are nature, and the overall quality is improved[2].

\subsection{Basic features of research-oriented teaching basic features - students subjectivity}

Research-oriented teaching focuses on "issues to explore". It aims to cultivate students' curiosity, guide independent consideration and innovation and embody the "student-centered" teaching philosophy [3]. The entire teaching process follows "studentcentered, teacher-led". Students carry out research and thematic studies independently to explore new knowledge and summary learning experiences and outcomes. By this method, students could be from passive recipients to active learners.

\subsection{Basic features of research teaching basic features-teachers' leading}

Under the research teaching, teachers must transform their roles from indoctrinating knowledge teachers to directors and promoters who can help students study on their own initiative [4]. Professor Zhong Qiquan thought that "research teaching" was learning activities. "Students selected and determined research topics from student life and social life under the guidance of teachers to acquire knowledge, apply knowledge and solve problems initiatively."[5] Therefore, teachers' leading is a key to cultivate the students' subjectivity. Taking a variety of teaching methods, setting research topics, providing finding ways of relevant knowledge and answering confused problems are purpose of teachers leading. It makes a sense of enlightenment, rational guidance and guides students to apply innovative thinking. 


\subsection{Basic features of research teaching basic features - practical innovation}

Practical innovation is an important objective of implementing research teaching. Cultivation of innovative talents must make innovative consciousness and innovative ability cultivated in the first place [6]. Innovation begins with questions and comes from practice. Strict teaching content and practice can create a good platform for independent learning atmosphere and environment for students. For students from science and engineering colleges stressed the importance of social practice, the research teaching is able to train students effectively to design production system and product development, project development and engineering innovation.

\section{DEVELOPMENT ABROAD}

Putting students in the education teaching system is the core of the western developed countries government direction of the reform of higher education [7]. In the late $19^{\text {th }}$ century to early $20^{\text {th }}$ century, American progressives mentioned "Question teaching method", such as John Dewey and Kilpatrick, encouraged "Learning by doing" education thought [8]. In the 1990s, many European countries carried out exploration and practice about research teaching. Among them, many counties acquired good effect, such as Germany project oriented learning method, Denmark project teaching, Sweden question learning method and so on [9]. Meanwhile, a part of Asia countries also carried out reform based on research teaching. In 1996, the Japanese central education council published report: $<$ About our country education expectation in 21 century >, and came up with "train students find problems by themselves"[10].

Since 1990s, our country institutions of higher teaching have carried out research teaching program in succession. For example, Tsinghua University mentioned Students' scientific research training (SRT) program, and Zhejiang University carried out Students' scientific research training program (SRTP). On June 23, 2010, the ministry of education convoked "Excellent engineers education program" kick-off meeting in Tianjin, that is an important reform program of our country implement research teaching, also a major initiative to improve our country engineering education from big country to powerful country.

\section{DISCUSSION}

Hongbao (1767-1835), which is a famous Germanic educator, once came up with the point of the unification among teaching, studying and research.
He claimed that the university professors' main task is to guide students to learning and researching. Thus, the center of research-oriented teaching mode should be learning and researching and emphasizing the relationship between teaching and researching which will benefit each other.

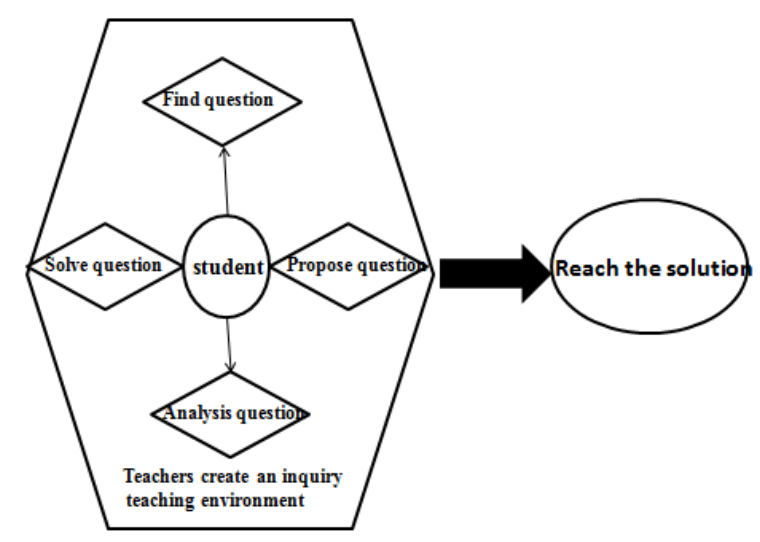

Figure 1: An inquiry teaching environment

From the Figure 1, it can be seen that the question inquiring mode emphasizes the dominance of teachers. Teachers create an inquiry teaching environment which is student-centered, putting the inquiring in the surface, giving students to explore direction, encouraging students to find out problems by themselves and then getting the solution.
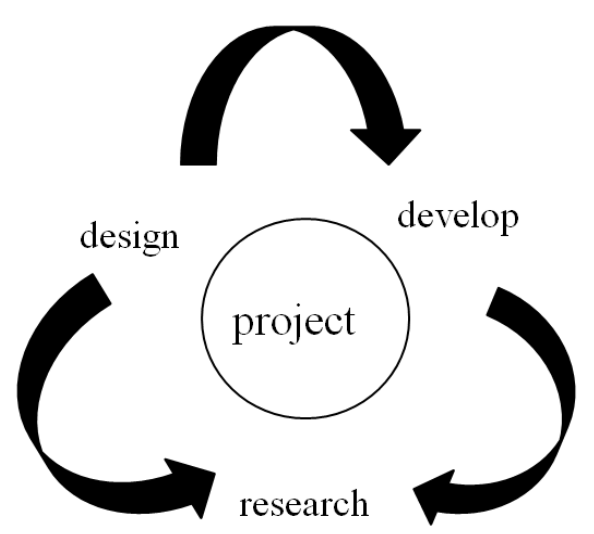

Figure 2: Project participating mode

Figure 2 indicates a pattern diagram of project participants. It takes the project as an object of study, applies the learned knowledge and chooses effective solution to project tasks by participating in the whole process of the project. In the actual project process, Students apply the theoretical knowledge learned in the classroom synthetically. They deal with local and overall, person and group, and achieve integration of knowledge and innovation of practice finally.

\section{CASE STUDY}

The article discussed the application of research teaching mode in the subject of Thermal 
Engineering. It took the subject in Tianjin Commerce University as an example. The "Plan of Training Predominant Engineers" (PTPE) aims to conduct the important revolution. To conduct the PTPE, Tianjin University of Commerce has been looked as one of the first nine experimental units, and there were 30 experts had been chosen as the members of the first PTPE class of the subject that was Thermal Energy and Power Engineering.

The PTPE class mainly adapted the style of " $3+0.5+0.5 "$ " To illustrate, the class will make a individual plan according to different students' situation. In addition, the laboratory courses will occupy an increasing proportion of the whole module in the condition of stable theory contents. Moreover, the students who are arranged in The Centre of Engineering Practical Education" need to spend half a year on completing the module, and they also will be arranged into relevant companies to finish the dissertation. To improve the quality of education, there are two supervisors which are respectively schooling supervisor and companying supervisor will be arranged to guide the students [11]. Directive standard of PTPE clearly claimed the demands of knowledge and awareness in predominant engineer cultivation ${ }^{[12]}$, and that of Tianjin University of Commerce will conduct the researching section. As a result, new experts will saved for national heat energy filed. Nowadays the 30 students of 2012 have achieved an excellent performance, among of these, majority of these students have signed a contract with relevant companies earlier than usual. In addition, there are 4 of these students have received the offer from foreign universities.

The revolution of researching education is a systematized engineering, it is significant and needs to be effectively managed and guided. Although there are policies to protect the research teaching and the trends promote it, research teaching is still limited so far. To establish operational mechanism to adapt to the research teaching and carry out the reform research teaching is the only way for cultivating applied innovation talents. It is also the most strong touch color in the history of higher education reform.

\section{ACKNOWLEDGEMENT}

Reform research projects of Tianjin undergraduate teaching quality and teaching. Project number: B020810 .

\section{REFERENCES}

[1] Hongyan Wen. 2002. Statements of foreign headmaster on Chinese University. Education, Technology, Culture

[2] Changxin Li. 2009, (59-61). Discusses of researching education in University, Nanjing Agriculture University

[3] Huiling, Li Xiong, Haiming Long. 2010, (119-122). Researching education and researching learning analysis, Social Scientist

[4] Jian Lin. 2011, (5-15) Researching learning of predominant engineers cultivation. Higher engineering education research

[5] Qiquan Zhong, 2005, (02). Basic statements of researching learning. Shanghai education scientific research

[6] Jie Zhong, Song Rao. 2009. Promote researching learning and cultivate creating experts. Chinese collective economy

[7] Junying Zhao, Yachun Wu, Jian Sun. 2008(14), Methods researching of researching education in university. Chinese scientist information

[8] Higher Education Students at the Heart of the System, UK government commerce creating and skills, June 2011

[9] Jie Zhong, Song Rao. 2009. Promote researching learning and cultivate creating experts. Chinese collective economy

[10] Hui Lu, 2013. Practice researching and style construction of researching education in science and engineering university. Dalian, Science and Engineering University

[11] http://www.tjcu.edu.cn/Notice/teach/20120814/teach4150. html

[12] Jian Lin. 2010. Standards production of cultivate predominant engineers plan, High level engineering education researching. 